\title{
The Relationship between Iranian EFL Learners' Academic Self-schemas and Their Willingness to Communicate
}

\author{
Farzaneh Dehghan $^{1, *}$, Azita Ajdari \\ ${ }^{1}$ Farhangian University, Shahid Bahonar Branch of Shiraz, Iran \\ ${ }^{2}$ Islamic Azad University, Marvdasht Branch, Iran
}

Copyright $\bigcirc 2017$ by authors, all rights reserved. Authors agree that this article remains permanently open access under the terms of the Creative Commons Attribution License 4.0 International License

\begin{abstract}
This study examined how Iranian EFL learners' level of academic self-schema is related to their willingness to communicate (WTC). To this end, 243 female undergraduate EFL university students from Islamic Azad University, Shiraz Branch (convenience sampling) completed two questionnaires, namely, a WTC and a researcher-made self-schema questionnaire. The latter questionnaire was developed based on two types of self-schemas, namely, entity and incremental. Entity self-schema regard ability as fixed or unchangeable while incremental self-schema regards it as improvable and changeable in future. Correlation results $(r=0.380, p<0.000)$ indicated a statistically moderate but significant relationship between self-schema and WTC scores. To measure the predictability of WTC scores on the basis of the two levels of self-schema scores, a linear regression was calculated. The entity $\mathrm{R}$ value $(0.165)$ illustrates a low correlation between entity self-schema and WTC while the incremental $\mathrm{R}$ value $(0.516)$ shows a moderate correlation between the incremental self-schema scores and WTC. It means that $26.6 \%$ of the WTC can be predicted by the incremental self-schema scores. The findings of the present study showed that the incremental self-schema can be an important factor in the EFL learners' willingness to communicate because it is related to choices and actions that affect learning.
\end{abstract}

Keywords Academic Self-schemas, Willingness to Communicate, Entity Self-schema, Incremental Self-schema

\section{Introduction}

Second language researchers have emphasized the importance of communication as a crucial component of modern language instruction. Accordingly, the notion of Willingness to Communicate (WTC), which is actually the intention and desire to initiate communication, plays a key role in learning a second/foreign language [1]. MacIntyre, Baker, Clement, and Donovan [2] believe that in spite of the importance of communication in second language instruction and the long-accepted view that learners need practice in speaking to learn, some language learners prefer to stay silent. The fact is that many EFL students who prefer to remain silent in foreign language classes have formed wrong schemas in relation to their inability to communicate effectively in a foreign language. Even if learners are well-equipped with communicative skills, they may prefer not to speak. These personal impressions of one's own capabilities can in various ways influence the interest of individuals in establishing communications. Understanding how human beings feel, respond, believe, and value is an exceedingly important aspect of a theory of second language acquisition. It could easily be claimed that no successful cognitive or affective activity can be carried out without some degree of positive self-schemas. Malinowski [3] noted personality development universally involves the growth of a person's concept of self, acceptance of self and reflection of self as seen in the interaction between self and others. As a significant constituent of the self, a self-schema about ability to control and operationalize one's academic potentials would have significant impact on the processing of intrinsic and extrinsic stimulus information in a social situation such as a classroom. As a result of differential processing of information, one's academic self-schemas can influence one's performance in class.

Woolfolk, Winne, and Perry [4] maintain that motivation to learn could be increased through setting learning goals and being task-involved. Beliefs about ability can affect motivation to learn. In the case of adults, there are two basic concepts of ability that are the entity view of ability and the incremental view of ability. The entity view supposes that 
ability is a stable, uncontrollable attribute. In other words, it is a characteristic of the individual that cannot be changed. According to this view, some people possess more ability compared to others, but the amount each person has is set. The second view, i.e., the incremental view of ability suggests that ability is unstable and controllable: "an ever-expanding repertoire of skills and knowledge" [5, p. 144]. Hard work, study, or practice can augment knowledge and thus improve ability. In other words, the entity self-schemas consist of a relatively stable representation of aspects of the self, including different abilities. The incremental self-schemas, on the contrary, are the individual's ever-changing state. They believe in the promoting state of one's abilities over time. The changes in the incremental self-schemas then prompt changes in behavior [6].

Taking into account the importance of communication and willingness to communicate in learners' achievements in language learning, it is not researched enough in Iranian context how students' ideas about their academic abilities or self-schemas can be related to their willingness to communicate. Understanding the connection between the two factors can help teachers and educators to better understand their students' eagerness or hindrance in communicating in a foreign language classroom. To these ends, this study aims at exploring the relationship between Iranian EFL learners' academic self-schemas and their willingness to communicate in English. Further, the study tries to find out the extent to which the two types of self-schema, namely entity and incremental, can predict the degree of WTC in EFL learners.

\section{Review of Literature}

\subsection{Academic Self-schema}

Academic self-schemas or perceptions about self-capabilities in academic contexts have been proved to play an important role in the academic achievement. Weaver believes that "students' self-schemas of their capability to learn a second language are significant determinants of their learning behaviours, endeavour, and persistence" [7, p. 86]. As a result, these beliefs affect language achievement and course success. As clarified by Williams and Burden [1997, cited in 8], this may be due to the fact that highly self-schema learners are more committed to learning L2 and work harder to avoid failure, and they usually link failure to insufficient efforts or skills. Kim [9] believed that self-schemas will be raised by successes and it will be lowered by failure, but when a strong sense of self-schema is developed, a failure may not have much impact. McCroskey and Richmond [10] argue that research of findings from several academic domains have demonstrated that students' judgments of their own academic capabilities, or self-schema beliefs, influence their academic behaviors and performances.
A study regarding self-schemas and L2 achievement is Toth [11] who investigated whether student-perceived self-schema beliefs were predictors of their academic achievement. Results indicated that students' self-schema beliefs were positively related with their academic achievement. Williams and Burden [12] stated that earlier SLA studies have found a strong relation between self-schemas and academic achievement. As stated by Williams and Burden [12], this result may be due to the fact that highly self-schema learners are more committed to learning L2 and work harder to avoid failure, and they usually link failure to insufficient efforts or skills.

Kim [9] believed that self-schemas will be raised by successes and it will be lowered by failure, but when a strong sense of self-schema is developed, a failure may not have much impact. McCroskey and Richmond [10] argue that research of findings from several academic domains have demonstrated that students' judgments of their own academic capabilities, or self-schema beliefs, influence their academic behaviours and performances. Fraser, Fisher and McRobbie [13] examined the relationship between EFL learners' self-schema beliefs and English achievement at two large universities in Taiwan. Results indicated that there was a significant and positive relationship between self-schema beliefs and their achievement.

\subsection{Willingness to Communicate}

As was mentioned, self-schemas are constructed schemas about self and in particular about one's abilities [4]. This view could be closely related to attribution theory and self-efficacy approaches which focus on the reasons provided by people about their failures and successes [14, 15]. According to these views, learners attribute their success or failure either to external (difficulty of the task and luck) or to internal factors (ability and effort). In other words, those learners who have a high sense of self-efficacy tend to see themselves capable of doing any task with whatever level of difficulty, and if they cannot reach their decided goals, they will mostly attribute it to not enough effort and rarely may they attribute them to any kind of excuses like bad luck.

Willingness to communicate is a variable closely related to attribution and self-efficacy factors (Brown, 2014). According to literature, willingness to communicate may have its roots in many cognitive and affective factors including self-efficacy and self-confidence [8]. In addition, some studies [16, 1] have found that willingness to communicate is a dynamic system which can vary significantly over time. Taking the definition of self-schema into account that self-schema could be defined in terms of being regarded as incremental (dynamic and changeable) or entity (stable and fixed), a relationship may exist between these two different types of self-schema and willingness to communicate because both are considered as related to attribution and self-efficacy beliefs. However, no study has in particular addresses the relationship between self-schema 
beliefs and WTC. This is the question that this study aims to answer.

\section{Method}

\subsection{Participants}

To achieve the objectives of the study, a total of 243 female undergraduate EFL university students from Islamic Azad University, Shiraz Branch (convenience sampling) with the age range of 18 to 42 took part in this study. They were majoring in translation studies and teaching English as a foreign language and were from different academic years.

\subsection{Instrumentation}

Two instruments were utilized in this study. The slightly modified 29-item L2WTC questionnaire from Gol, Zand-Moghadam, and Karrabi [17] was used in this study to measure WTC. The Cronbach's alpha reported by Gol, Zand-Moghadam, and Karrabi [17] was 0.73. The Cronbach's alpha obtained in the main procedure of the present research was 0.763 .

The second instrument employed in this study was the researcher-constructed academic self-schema questionnaire taken from the literature (e.g., [4]). The self-schema questionnaire was pilot-studied with 26 female students from Farhangian University, Shiraz Branch. The items in the questionnaire were constructed based on the two types of entity and incremental self-schemas. The content validity of the questionnaire (92\%) was calculated based on expert opinion, taking into account the two most prominent criteria: the relevance of the items to the study, and the comprehensibility of the items. Furthermore, the reliability of the questionnaire (internal consistency) was calculated to be .76 and the Cronbach's alpha was 0.947 .

Exploratory factor analysis was administered. The KMO measure of sampling adequacy was small in size (0.391). But Bartlett's Test of Sphericity (105.84, DF=3) was significant (0.000) and indicated existence of significant factors and, therefore, variables were dependent upon each other.

The content validity of all items was determined as 0.920 .
The internal consistency of questions showed a high correlation of all questionnaire items. Based on the results of the pilot study, no item needed modification. Also none of the items was deleted from the original questionnaire. As a result, the Academic Self-Schema Questionnaire with 20 items was utilized in the main phase of the study. The Cronbach's alpha for the main administration of the present research was 0.74 .

\subsection{Data Collection and Analysis}

In the main phase of the study, the participants answered the two questionnaires in one session. They were provided enough information before filling the questionnaires. Correlation coefficient and linear regression were used to analyze the garnered data.

\section{Results}

With regard to correlation coefficient $(\mathrm{r}=0.380)$ and the significance level (0.000) there is a statistically significant relationship between the WTC and the Self-Schema scores at the 0.01 level.

To measure the predictability of WTC scores on the basis of the two levels of self-schema scores, a linear regression was calculated between self-schema scores and WTC. The results are illustrated in Tables 1 and 2 .

As the $\mathrm{R}$ value $(0.165)$ illustrates, there is a little correlation between entity self-schema and WTC. The $\mathrm{R}^{2}$ value (0.027) indicates that $2.7 \%$ of the WTC can be predicted by the entity self-schemas $(0.027 \times 100=2.7)$.

To measure the predictability of WTC scores based on the incremental self-schema scores, a linear regression was calculated between the incremental self-schema scores and WTC. The results are illustrated in Table 2.

As the $\mathrm{R}$ value (0.516) illustrates, there is medium correlation between the incremental self-schema scores and WTC. The $\mathrm{R}^{2}$ value $(0.266)$ indicates that $26.6 \%$ of the WTC can be predicted by the incremental self-schema scores $(0.266 \times 100=26.6)$.

Table 1. The results of the regression analysis of WTC and entity self-schema scores

\begin{tabular}{|c|c|c|c|c|}
\hline \multicolumn{5}{|c|}{ Model Summary } \\
\hline Model & $\mathrm{R}$ & R Square & Adjusted R Square & Std. Error of the Estimate \\
\hline 1 & $.165 \mathrm{a}$ & .027 & .023 & 8.79037 \\
\hline \multicolumn{5}{|c|}{ a. Predictors: (Constant), SS_entity } \\
\hline
\end{tabular}

Table 2. The results of the regression analysis of WTC and incremental self-schema scores

\begin{tabular}{|c|c|c|c|c|}
\hline \multicolumn{5}{|c|}{ Model Summary } \\
\hline Model & $\mathrm{R}$ & $\mathrm{R}$ Square & Adjusted R Square & Std. Error of the Estimate \\
\hline 1 & $.516 \mathrm{a}$ & .266 & .263 & 7.63403 \\
\hline \multicolumn{5}{|c|}{ a. Predictors: (Constant), SS_incremental } \\
\hline
\end{tabular}




\section{Discussion}

The present study set out to investigate the relationship between self-schemas and WTC of EFL learners. The results of correlational analysis showed a relationship between self-schema scores and WTC among learners. The correlation results between entity vs. incremental self-schema and WTC, however, revealed different relationships. It was shown that the relationship between incremental self-schema and WTC was far higher (0.516) than that of entity self-schema (0.165). Generally put, "a schema is a mental picture or understanding of something we have learned" [Smilkstein, 18, p. 1]. She further defined schema as "a representation or construct in our mind-a mental picture or understanding of something. It is "constituted of the elements or characteristics of the things we know" [18, p. 3]. As mentioned before, the entity self-schemas consist of a relatively stable representation of aspects of the self. The incremental self-schemas, on the contrary, are the individual's ever-changing state and draw on aspects of the entity self-schemas in response to situational inputs. The desire to communicate is interactive by nature and, therefore, requires physical and mental flexibility on the side of the learners. Individuals with higher incremental self-schema scores gather information, evaluate alternatives, and make decisions [19]. They enjoy higher cognitive complexity, motivation, openness, and autonomy all of which are key factors in learning a new language. The existence of a moderate correlation may indicate that the learners find the classroom environment pleasant and friendly. Mohseni and Niknejad's [20] study supports this idea and confirms that context plays a role in encouraging learners to initiate conversation.

As the WTC and Incremental SS correlation (0.516) illustrated, it can be concluded that incremental self-schema is very important in willingness to communicate because it relates to choices and actions that affect learning "such as goal-setting persistence, resilience, effort, and strategy" [Shaughnessy, 21, p. 172. Several studies have so far depicted that one's understanding of his/her own ability plays a vital role in his/her performance. Magogwe and Oliver [22] claimed that positive self-schemas are one of the elements that could shape the learner's ability to perform effective communication. Mahyuddin et al. [23] also believed that secondary school students' achievement in English language improved when they enjoyed positive self-schemas about their abilities.

Students with positive self-schemas are likely to value achievement and see ability as improvable. That is why they concentrate on learning goals in order to increase their skills and abilities. Since failing does not threaten these students' sense of competence and self-worth, they are not scared of failure. This allows them to set fairly challenging goals, take risks, and cope with failure constructively. These students generally attribute success to their own effort and assume responsibility for learning. They also have a strong sense of self-efficacy. One of the abilities they possess is that they perform best in competitive situations, learn fast, have more self-confidence and energy, are more stimulated, and are eager to learn "the rules of the game" so that they can succeed. All of these factors make for persistent, successful learning $[24,25,26]$.

The findings of the present study with regard to moderate correlation between incremental self-schema and WTC proves that if competent target language learners expand their WTC to the outsides of the sanctum of the language classroom, the important social and pedagogical goals of language instruction, which mainly intend to bring about contact among students and encourage them to initiate communication [27] will be fulfilled. The entity self-schema scores did not correlate highly with WTC. One explanation might be the probability that they act like barriers to language learning. These barriers are attributed to two 'enduring influences' and 'situational influences' enigmas [27]. Enduring influences surface when a fluent mother-tongue speaker outside the class becomes mute in the FL class. The situational influences, on the other hand, occur when learners who are competent foreign language speakers become unwilling to snatch the FL communication opportunity in class for some transient, situationally dependent reason [27].

The medium level of correlation between WTC and self-schemas may indicate the fact that Iranian EFL university students do not need a good command of English communicative competence to achieve their academic or societal goals. It can, therefore, be inferred that Iranian EFL students may not depend much on their communicative competence and qualifications for their academic achievement and many students may keep silent during the class time. However, the relationship between self-schemas and WTC is statistically significant, which means that WTC is related to students' self-schemas. Ghonsooly, Hosseini Fatemi, and Khajavy's [28] study also confirmed the findings of this study. They, too, noticed that except for some courses such as conversation classes, topic discussion classes and oral reproduction of story courses, Iranian English majors did not need a good command of English speaking proficiency to pass their exams, which was due to the fact that a majority of examinations required students to write their answers. To these writers, therefore, academic achievement did not depend much on good speaking proficiency, and many students kept silent in class. The second justification was that most of Iranian classes are teacher-based, where the teacher is approximately the sole speaker and social communicative needs are not emphasized.

Findings of this study confirm those of Weaver [7] who asserted that students' self-schemas of their competence to learn a foreign language are indices of their learning behaviours, venture, and perseverance. The reason may be that there is a relationship between WTC and self-schemas, as confirmed by the findings of this study.

This study was in line with McCroskey and McCroskey's 
$[29,30]$ findings that there is relationship between WTC and incremental self-schema about one's abilities. There was also a consistency between the findings of this study and those of Yashima, Zenuk-Nishide, and Shimizu [8]. They found a strong relationship between self-efficacy and willingness to communicate. This may indicate that there is an association between willingness to communicate and higher self-schema beliefs. There are some researches (e.g., [12]) which have examined the relationship between self-schema beliefs and willingness to communicate. These researches suggest that self-schema beliefs correlate positively with willingness to communicate. This correlation may be due to the fact that learners with incremental self-schema are more committed to learn FL. They also work harder to avoid failure, and they usually link failure to inadequate effort or skill. This research also confirmed the results of Yashima's [31] study. She proved that the students' positive self-schemas in foreign language communicative competence were crucial for their willingness to be involved in FL communication.

It is clear that there is an association between self-schema and the willingness to communicate and, therefore, ability towards learning English as a foreign language. It is recommended that schools and universities conduct speaking courses at different levels, e.g., speech workshop course. The support from teachers and peers in the form of formulating positive and constructive self-schemas and helping students believe in their own abilities can help students in building confidence by responding to the questions and participating in conversations conducted in English as a foreign language.

\section{Conclusions}

With regard to higher correlation between incremental schemas and WTC $(\mathrm{R}=0.516)$ compared with the entity schemas $(\mathrm{R}=0.165)$, it is concluded that students with incremental self-schemas were more willing to participate in the language-learning activities and accomplish the tasks in the classroom. Appropriate statistical procedures were used to obtain the required responses to see whether there was any relationship between EFL learners' willingness to communicate and their academic self-schemas. The present study confirmed ideas that maintain self-schema is an influential factor in speaking performance, oral proficiency, and communicative competence. Further research can examine the relationship between types of self-schemas on the one hand, and different communication strategies, internal and external types of motivation, goal orientations and self-regulation constructs, on the other.

\section{REFERENCES}

[1] MacIntyre, P., \& Legatto, S. (2011). Talking in order to learn: Willingness to communicate and intensive language programs. The Canadian Modern Language Review, 59(4), 589-607.
[2] MacIntyre, P., Baker, S. C., Clément, R., \& Donovan, L. A. (2003). Talking in order to learn: willingness to communicate and intensive language programs. Canadian Modern Language Review, 59, 589- 607.

[3] Malinowski, B. (1923) 'The problem of meaning in primitive languages', in C. K. Ogden and I.A. Richards, (1923) The Meaning of Meaning. London: Kegan Paul.

[4] Woolfolk, A. E., Winne, P. H., \& Perry, N. E. (2011). Educational Psychology, (5 ${ }^{\text {th }}$ Canadian Edition with My Education Lab). Toronto: Pearson Education Canada.

[5] Dweck, C. S., \& Bempechat, J. (1983). Children's theories of intelligence: Consequences for learning. In S. Paris, G. Olson, \& H. Stevenson (Eds.), Learning and motivation in the classroom (pp. 239-255). Hillsdale, NJ: Erlbaum.

[6] Schutte, N. S., \& Malouff, J. M. (2012). Adaptive emotional functioning: A comprehensive model of emotional intelligence. In C. Mohiyeddini (Ed.), Psychology of emotions. Hauppauge, New York: Nova Science Publishers.

[7] Weaver, C. (2005). Using the Rasch model to develop a measure of second language learners' willingness to communicate within a language classroom. Journal of Applied Measurement, 6(4), 396-415.

[8] Yashima, T., Zenuk-Nishide L., \& Shimizu, K. (2004). The influence of attitudes and effect on willingness to communicate and second language communication. Language Learning, 54, 119-152.

[9] Kim, S. J. (2004). Exploring Willingness to Communicate (WTC) in English among Korean EFL (English as a Foreign Language) Students in Korea: WTC as a Predictor of Success in Second Language Acquisition. Unpublished Doctoral Dissertation, Columbus: Ohio State University.

[10] McCroskey, J. C., \& Richmond, V.P. (1987). Willingness to communicate and interpersonal communication. In J.C. McCroskey and J. A. Daly (Eds.), Personality and interpersonal communication, (129-156). Beverly Hills, CA: Sage.

[11] Toth, Z. (2007). Predictors of foreign-language anxiety: Examining the relationship between anxiety and other individual learner variables. In J. Horváth \& M. Nikolov (Eds.), Empirical studies in English applied linguistics (pp. 123-148). Pécs: Lingua Franca Csoport.

[12] Williams, M., \& Burden, R. (1997). Psychology for language teachers: A social-constructivist approach. Cambridge: Cambridge University Press.

[13] Fraser, B. J., Fisher, D. L., \& McRobbie, C. J. (1996). Development, validation, and use of personal and class forms of a new classroom environment instrument. Paper presented at the Annual Meeting of the American Educational Research Association, New York.

[14] Bandura, A. (1993). Perceived self-efficacy in cognitive development and functioning. Educational Psychologists, 28, 117-148.

[15] Weiner, B. (2000). Intrapersonal and interpersonal theories of motivation from an attributional perspective. Educational Psychology Review, 12, 1-14.

[16] MacIntyre, P. (2007). Willingness to communicate in the second language: understanding the decision to speak as a volitional process. Modern Language Journal, 91, 564-576. 
[17] Gol, M., Zand-Moghadam, A., \& Karrabi, M. (2014). The construct of willingness to communicate and its relationship with EFL learners' perceived verbal and nonverbal teacher immediacy. Issues in Language Teaching (ILT), 3(1), $135-160$

[18] Smilkstein, R. (1991). A Natural Teaching Method Based on Learning Theory. Gamut, 36, 12-15.

[19] Shahsavani, S., Shahsavar, Z., \& Sahragard, R. (2014). On the relationship between willingness to communicate and identity processing styles of the Iranian advanced EFL learners. International Journal of Language Learning and Applied Linguistics World (IJLLALW), 5(1), 57-67.

[20] Mohseni, A., \& Niknejad, S. (2013). Willingness to communicate: A critical overview. International Journal of Educational Research and Development. 2(2), 041-048.

[21] Shaughnessy, M. F. (2004). An interview with Anita Woolfolk: The educational psychology of teacher efficacy. Educational Psychology Review, 16, 153-176.

[22] Magogwe, J. M., \& Oliver, R. (2007). The relationship between language learning strategies, proficiency, age and self-efficacy beliefs: A study of language learners in Botswana. System, 35, 338-352.

[23] Mahyuddin, R., Elias, H., Cheong, L. S., Muhamad, M. F., Noordin, N., and Abdullah, M. C. (2006). The relationship between students' self-efficacy and their English language achievement. Jurnal Pendidik dan Pendidikan, 21, 61-71.

[24] Alderman, M. K. (1985). Achievement motivation and the pre-service teacher. In M. K Aldeman \& M. W. Cohen (Eds.),
Motivation theory and practice for pre-service teachers ( $\mathrm{pp}$. 37-51). Washington, DC: ERIC Clearinghouse on Teacher Education.

[25] McClelland, D. C. (1985). How motives, skills, and values determine what people do. American Psychologist, 40, 812825 .

[26] Morris, J. (1991). Pride against prejudice: transforming attitudes to disability. New Society.

[27] Gregersen, T \& MacIntyre, P. D (2014). Capitalizing on Language Learners' Individuality: From Premise to Practice. Multilingual Matters.

[28] Ghonsooly, B., Hosseini, Fatemi, A., \& Khajavy, G. H. (2013). Examining the relationships between willingness to communicate in English, communication confidence, and classroom environment. International Journal of Research Studies in Educational Technology, 3(1).

[29] McCroskey, J. C., \& McCroskey, L. L. (1986a). Correlates of willingness to communicate. Paper presented at the annual convention of the Western Speech Communication Association, Tucson, AZ.

[30] McCroskey, J. C. \& McCroskey, L. L. (1986b). Self-report as an approach to measuring communication competence. Paper presented at the annual convention of the Central States Speech Association, Cincinnati, $\mathrm{OH}$.

[31] Yashima, T. (2002). Willingness to communicate in a second language: The Japanese EFL context. The Modern Language Journal, 86(1), 54-66. 